\title{
Fibroscopic examination on ENT patients in COVID-19 era
}

\author{
Bogdan Popescu ${ }^{1,2}$, Oașă Irina Doinița ${ }^{1}$, Cristian Bălălău ${ }^{1,3}$, Răzvan Scăunașu ${ }^{1,4}$, \\ Felicia Manole ${ }^{5}$, Maria Domuța ${ }^{5}$, Alina Lavinia Antoaneta Oancea ${ }^{1,2}$ \\ ${ }^{1}$ CAROL DAVILA UNIVERSITY OF MEDICINE AND PHARMACY, BUCHAREST, ROMANIA \\ ${ }^{2}$ ENT DEPARTMENT, COLTEA CLINICAL HOSPITAL, BUCHAREST, ROMANIA \\ ${ }^{3}$ GENERAL SURGERY DEPARTMENT, SAINT PANTELIMON EMERGENCY HOSPITAL, BUCHAREST, ROMANIA \\ ${ }^{4}$ GENERAL SURGER DEPARTMENT, COLTTEA CLINICAL HOSPITAL, BUCHAREST, ROMANIA \\ ${ }^{5}$ FACULTY OF MEDICINE AND PHRAMACY, ORADEA, ROMANIA
}

\section{AB STRACT}

Patients benefit from the use of telescopes and flexible fiber optics when are examined by the ENT specialist. It is not mandatory in all situations but in most cases, some form of optical endoscopic examination of the nasal cavities, pharynx or larynx is needed. There is some reluctance to use this kind of method in patients in COVID 19 era since this is a maneuver that can generate aerosols and thus increase the chance of transmitting SARS-Cov-2 virus. There are several precautions that can be considered and we offer an insight on how fibroscopic examination can be performed with smaller risk for the physician. The question that we address is whether it is safe or not to perform this procedure and in what conditions.

\section{Category: Review}

Received: March 12, 2020

Accepted: May 17, 2020

Keywords:

COVID-19, endoscopy, ENT

*Corresponding author:

Răzvan Scăunaşu,

Carol Davila University, Department of General Surgery, Colțea Clinical Hospital, Bucharest, Romania

E-mail: razvan.scaunasu@gmail.com

\section{Introduction}

The SARS-Cov-2 virus emerging from China rapidly turned into a world pandemic, leading health care systems around the world into ever changing paradigms. This presumed respiratory virus was declared a pandemic as of March, 2020 [1]. The unpredictable evolution of COVID19 is the main reason for constant updates in health care protocols with the direct intent of slowing the spread of the virus [2]. No specialty escaped the need for guidelines and procedures that comprise the entire spectrum of diagnosis and therapy, thus otolaryngologists were obliged to update their practice. ENT examination was, and still is, considered with high risk since in involves the examination of the organs in which the virus takes contact with the underlying mucosa and where multiplication occurs. This is the basis for specimen swab collection included in the RT-PCR detection of SARS-Cov-2. Since ENT examination includes maneuvers that can generate aerosols, special care must be taken to assure the safety of the medical staff and patients.
Methods. This paper shows ENT practice in Colțea Clinical Hospital, Saint Pantelimon Emergency Hospital and ENT specialists from Oradea Faculty of Medicine, being based on the current guidelines available in Romania, suggested by the Romanian Society of ENT and cervico-facial Surgery. These guidelines have been adapted for clinical practice from French and British societies of ENT guidelines. All data were confirmed by world health databases and search strategy was directed by the association of COVID-19 and SARS-Cov-2 along with nasal, pharynx and larynx endoscopy. Our focus was to determine whether our practice is similar to our European fellow ENT specialists and, in this case, what can be improved.

\section{Discussions}

ENT examination is dominated by the use of endoscopy, as it is the perfect exploration of hidden places/ organs in the head and neck region. This is part of the clinical examination with no concern on other imaging studies. Different types of endoscopy have been developed 
from rigid to flexible endoscopy, with or without the possibility of making diagnosis via biopsy, digital subtraction images using filtered light for examining blood vessels located in the mucosa and submucosa such as narrow band imaging technique and also contact endoscopy [3]. It is safe to say ENT examination has less sensitivity and specificity in the absence of endoscopy. This is why endoscopy needed to remain in the good clinical practice of otolaryngologists, the lack of which would be considered as inadequate clinical investigation of the ear, nasal cavities, paranasal sinuses, pharynx and larynx [4].

Due to the direct investigation of the upper respiratory tract, ENT specialists are considered at high risk of exposure in terms of COVID 19 transmission. Direct visualization of the organs in the head and neck region is not directly harmful, still, maneuvers performed in this region increase the risk of sneezing, coughing and gagging by the patient. Endoscopy of the upper aero-digestive tract has the same risks of exposing ENT specialists to these consequences. Although endoscopy of the upper respiratory tract is not considered to generate aerosols, aerosolization might occur if the patient sneezes or coughs [5]. Not only the direct exposure to viral particles aerosolized during endoscopy are the issue but also the proximity of the physician performing the procedure and the possibility that viral particles may stay airborne for more than 3 hours [6].

\section{Indications}

Since telemedicine is a means of providing health care services, we implemented on-line platform for patients were non-contact medical opinion was formulated based on history and symptoms experienced by the patient. We found that most suitable for telemedicine are otologic problems since $65 \%$ of patients were successfully treated. Similar data were provided by Gilani et al. in a study concerning telemedicine in which they concluded that up to $80 \%$ of otologic pathology diagnosed and treated using telemedicine did not require further follow-up [7,8]. Still, this is not the case for patients with nasal, pharynx and larynx pathology for which medical appointments in the hospital were made. Unlike approaches like that used by Soldatova et al. we considered that clinical examination and endoscopy needed to be performed for patients with symptoms related to the pharynx, larynx and esophagus [9]. Not being able to differentiate symptoms that might hide oncology pathology we devised a protocol for endoscopic examination of suspect cases of malignancy [10].

This raised the question "Is it safe to examine patients using endoscopy in COVID 19 era?". The answer is not at hand since there is the risk of viral transmission via aerosols generated by sneezing and coughing during endoscopy.

\section{Alternatives}

Some alternatives are possible for replacing endoscopy in patients with COVID 19 symptoms or for patients that are at risk. Clinical history of the disease and non-invasive assessment may be an alternative for the routine endoscopy. Tests like SinoNasal Outcome Test (SNOT22), NOSE and VAS scores, acoustic rhinometry, blood tests and imaging studies are used to better assess specific symptoms, quantify nasal function and measure the quality of life. However, these tests are indirect measurements and prone to miss-interpretation but still an indicator for the need for surgery [11]. The best way to ensure proper patient sorting is to assess particular symptoms and their severity. We found that $45 \%$ of patients coming to the hospital for medical consult needed an upper aerodigestive tract endoscopy. This is in part due to the ENT oncology specific department and due to emergency cases.

\section{Procedure}

Prior to the clinical examination thorough screening is necessary for all patients. Thermal screening and filling a questionnaire concerning travel history, human contact and symptoms for COVID 19 are mandatory. Patients manifesting sneezing, cough, soreness of the throat, dysphagia or fever were tested with rapid tests for SARSCov-2 and endoscopy was performed in selected cases of seriously ill patients.

Preparation of the procedure included sanitation of hands, face mask for patients, full personnel protection equipment (PPE) for physicians (googles, FPP 2/3 face mask, cap, visor, gown, gloves, shoe covers), well aired rooms, bare minimum personnel and proper distancing $[12,13]$. Endoscopy was performed in all cases with video assistance instead of direct view. During the entire procedure the mouth of the patient was covered and we used nasal mesh to perform local anesthesia. No aerosolized sprays were use. All equipment was covered with disposable drapes and remaining surfaces were sanitized with $1 \%$ hypochlorite solution. All endoscopes were disinfected using standardized solutions provided by the manufacturer. Inspection of the oral cavity was performed in a timely fashion so that examination time was reduced to a minimum. Nasal cavity access for endoscopy seems to be the safest [14].

\section{Conclusions}

Even if the pandemic is reaching a second peak this year, we need to provide medical services for all patients, with emphasis on emergency and oncology patients. However, patients' symptoms screening leads to selected cases which will benefit from endoscopy examination. Precautions should be considered when examining each patient in terms of both patients and medical staff. We only use high levels of PPEs and we recommend that all 
examination of ENT patients be done in this manner. Bare minimum personnel and timed exposure are a must. Screening can include rapid tests but we cannot rely entirely on them. All endoscopy procedures required for proper diagnosis need to be performed with adequate PPEs and methodology to avoid misdiagnosis or delayed treatment.

\section{Conflict of interest disclosure}

There are no known conflicts of interest in the publication of this article. The manuscript was read and approved by all authors.

\section{Compliance with ethical standards}

Any aspect of the work covered in this manuscript has been conducted with the ethical approval of all relevant bodies and that such approvals are acknowledged within the manuscript.

\section{References}

1. WHO Director-General's opening remarks at the media briefing on COVID-19 - 11 March 2020. https://www.who.int/dg/speeches/detail/who-directorgeneral-s-opening-remarks-at-the-media-briefing-oncovid-19---11-march-2020

2. COVID 19: Operational Planning Guidelines to Support Country Preparedness and Response. www.euro.who.int/en/health-topics/healthemergencies/coronavirus-covid-19/training-courses

3. Kuhn FA. Role of endoscopy in the management of chronic rhinosinusitis. Ann Otol Rhinol Laryngol Suppl. 2004;193:15-18. doi:10.1177/00034894041130s505

4. Kennedy DW, Wright ED, Goldberg AN. Objective and subjective outcomes in surgery for chronic sinusitis. Laryngoscope. 2000;110(3 Pt 3):29-31. doi:10.1097/00005537-200003002-00008

5. Setzen G, Anne S, Brown EG, Denneny JC, Dubin MG, Ishman SL, Kuppersmith RB, Smith RV. Guidance for return to practice for otolaryngology-head and neck surgery part one.

https://www.entnet.org/sites/default/files/guidance_for _return_to_practice_part_1_final_050520.pdf

6. Setzen M, Svider PF, Pollock K. COVID-19 and rhinology: A look at the future. Am J Otolaryngol.
2020;41(3):102491.

doi:10.1016/j.amjoto.2020.102491

7. Gilani S, Bommakanti K, Friedman L. Electronic Consults in Otolaryngology: A Pilot Study to Evaluate the Use, Content, and Outcomes in an Academic Health System. Ann Otol Rhinol Laryngol. 2020;129(2):170174. doi:10.1177/0003489419882726

8. McCool RR, Davies L. Where Does Telemedicine Fit into Otolaryngology? An Assessment of Telemedicine Eligibility among Otolaryngology Diagnoses. Otolaryngol Head Neck Surg. 2018;158(4):641-644. doi:10.1177/0194599818757724

9. Soldatova L, Williams C, Postma GN, Falk GW, Mirza N. Virtual Dysphagia Evaluation: Practical Guidelines for Dysphagia Management in the Context of the COVID-19 Pandemic. Otolaryngol Head Neck Surg. 2020;163(3):455-458.

doi:10.1177/0194599820931791

10. Fried J, Imam SA, Lee JA, Nguyen SA. Nasal endoscopy protocols in the era of COVID-19 [published online ahead of print, 2020 May 14]. World $J$ Otorhinolaryngol Head Neck Surg. 2020;10.1016/j.wjorl.2020.04.007.

doi:10.1016/j.wjorl.2020.04.007

11. Tan MFM, Whitcroft KL, Mehta N, Schilder A, Leung TS, Andrews PJ. Investigating the nasal cycle using unilateral peak nasal inspiratory flow and acoustic rhinometry minimal cross-sectional area measurements. Clin Otolaryngol. 2019;44(4):518-524. doi:10.1111/coa.13313

12. Liang T.B. The First Affiliated Hospital, Zhejiang University School of Medicine; 2020. Handbook of COVID-19 prevention and treatment. https://esge.org/documents/Handbook_of_COVID-

19_Prevention_and_Treatment.pdf

13. Patel ZM, Fernandez-Miranda J, Hwang PH, et al. Letter: Precautions for Endoscopic Transnasal Skull Base Surgery During the COVID-19 Pandemic. Neurosurgery. 2020; 87(1): E66-E67. doi: 10.1093/neuros/nyaa125

14. Di Maio P, Traverso D, Iocca O, De Virgilio A, Spriano G, Giudice M. Endoscopic nasopharyngoscopy and ENT specialist safety in the COVID 19 era: the back endoscopy approach to the patient. Eur Arch Otorhinolaryngol. 2020; 277(9): 2647-2648. doi: 10.1007/s00405-020-06093-6 